\title{
Importance of Carbohydrates and Platelets in the Early Events of Cancer Metastasis
}

\author{
Hayato Kawakami and Hiroshi Hirano \\ Department of Anatomy, Kyorin University School of Medicine, Mitaka, Tokyo 181-8611
}

Received July 13, 1998; accepted April 9, 1999

\begin{abstract}
Mouse colon carcinoma (colon 26) cells were shown to attach to cultured hepatic sinusoidal endothelial cells only in the presence of PRP (platelet-rich-plasma). Most tumor cells first attached to the endothelial cells, not directly but via aggregated platelets. In addition, almost all of the tumor cells that were attached to the endothelial cells showed positive staining with ECA (Erythrina crystagalli agglutinin), whereas nearly half of the cells before adhesion were negative for ECA binding. ECA-positive cells, when separated from ECA-negative ones, revealed strong potency for metastasis
\end{abstract}

to the liver compared with ECA-negative ones. ECA-positive materials were extracted from the crude membrane fraction of colon 26 cells and were found to suppress the platelet adhesion. These results indicate that the ECA-positive sugar chains on the surface of colon 26 cells should mediate the binding between colon 26 cells and platelets and the attachment of tumor cells to the endothelium. The attachment of colon carcinoma cells to hepatic sinusoidal cells induced as above may cause the successive events in establishing cancer metastasis.

Key words: Metastasis, Platelet, Colon carcinoma, Carbohydrate, Lectin

\section{Introduction}

A variety of cell-surface molecules are thought to be involved in metastatic processes. Among them, cellsurface carbohydrates have been reported to enhance or suppress metastasis [3]. We previously found that the expression of $\mathrm{Le}^{\mathrm{x}}(\mathrm{Gal} \beta 1-4(\mathrm{Fuc} \alpha 1-3) \mathrm{GlcNAc})$ carbohydrate epitopes is related to the metastatic potential of mouse colon carcinoma (colon 26) cells [6]. In addition, the expression of $\mathrm{N}$-acetyllactosamine(Gal $\beta 1-4 \mathrm{GlcNAc})$-containing epitopes detected by the lectin from Erythrina crystagalli (ECA) has been enhanced significantly in the metastatic foci of colon 26 cells in the liver induced by injecting the cells into the spleen [5, 7]. In such a case, aggregation of platelets was often observed around the ECA-positive metastatic tumor foci in the liver even at an early period, within $30 \mathrm{~min}$, after the injection of the tumor cells into the spleen $[5,7]$. Moreover, enhanced

Correspondence to: Dr. Hayato Kawakami, Department of Anatomy, Kyorin University School of Medicine, Mitaka, Tokyo 181-8611, Japan.

Abbreviations: ECA, Erythrina cristagalli agglutinin; Gal, galactose; GlcNAc, N-acetyl-glucosamine; Fuc, fucose. adhesion of colon 26 cells to cultured hepatic sinusoidal endothelial cells by platelet aggregation was recently reported [15]. These results indicate that ECA-positive components on the colon 26 cell surface and circulating platelets may be involved in the early events of liver metastasis of this type of tumor cells. In the present study, employing an in vitro model system, the interactions among colon 26 cells, blood platelets and endothelial cells were investigated with special reference to the ECApositive carbohydrates.

\section{Materials and Methods}

\section{Animals and tumor cells}

Female BALB/c mice were obtained from Charles River Japan, Inc., Tokyo. A colon 26 mouse colon carcinoma cell line $[13,14]$ was kindly provided by Dr. T. Yamori (Cancer Chemotherapy Center, Japanese Foundation of Cancer Center). Liver metastases of colon 26 cells were obtained as follows: $0.1 \mathrm{ml}$ of colon 26 cell suspension $\left(5 \times 10^{5}\right.$ cells $\left./ \mathrm{ml}\right)$ in Eagles' minimum essential medium was injected into the spleen of BALB/c mice [5-7]. After two weeks, the livers were removed and metastatic foci were isolated. 


\section{Adhesion of colon 26 cells to the cultured HSE cells}

Mouse hepatic sinusoidal endothelial cells (HSE cells) [1] were provided by Dr. T. Yamori (Cancer Chemotherapy Center, Japanese Foundation of Cancer Center) and were confluently cultured in $35-\mathrm{mm}$ plastic dishes in the presence of RPMI 1640 medium under $5 \% \mathrm{CO}_{2}$-air at $37^{\circ} \mathrm{C}$. Platelet-rich-plasma (PRP) and platelet-poorplasma (PPP) were obtained from mouse blood anticoaggulated with sodium citrate by centrifugation at $1,200 \mathrm{rpm}$ and at $3,000 \mathrm{rpm}$ for $10 \mathrm{~min}$, respectively. A colon 26 cell suspension $\left(10^{6}\right.$ cells in $0.4 \mathrm{ml}$ RPMI medium) together with $0.4 \mathrm{ml}$ of PRP or PPP was added to HSE cell monolayer. After 0 to $60 \mathrm{~min}$ of incubation at $37^{\circ} \mathrm{C}$, the cells were washed twice with PBS and fixed with $2.5 \%$ glutaraldehyde-PBS for $1 \mathrm{hr}$ at room temperature. Part of the specimen was embedded in Epon and observed under a transmission electron microscope, and the rest was processed for lectin staining.

\section{Staining with lectin for light and electron microscopy}

Fixed cells were treated with 1\% BSA (bovine serum albumin)-PBS, then with biotinylated ECA (Erythrina crystagalli agglutinin; Vector Lab., Inc., CA, USA) at $25 \mu \mathrm{g} / \mathrm{ml}$ in $0.1 \%$ BSA-PBS at room temperature for $1 \mathrm{hr}$, followed by treatment with $\mathrm{ABC}$ reagent (Vector Lab., Inc.) for $30 \mathrm{~min}$. After the DAB (3,3'-diaminobenzidine) reaction had been performed, the cells were osmicated, removed from the dishes and embedded in Epon. One $\mu$ m-thick sections and ultrathin sections were observed under a light microscope and a transmission electron microscope, respectively. For the control, samples were stained with ECA in the presence of $0.05 \mathrm{M} \mathrm{N}$-acetyllactosamine (Toronto Res. Chem., Ont., Canada) which resulted in almost complete disappearance of the positive staining (data not shown).

\section{Separation of ECA-positive colon 26 cells}

A $2 \mathrm{ml}$ of colon 26 cell suspension $\left(5 \times 10^{5}\right.$ cells $\left./ \mathrm{ml}\right)$ was treated with biotinylated ECA $(25 \mu \mathrm{g} / \mathrm{ml}-\mathrm{PBS})$ at $0^{\circ} \mathrm{C}$ for $30 \mathrm{~min}$, followed by washing with PBS and treatment with streptavidin-labeled iron particles (BioMag, PerSeptive Diagnostics, MA, USA; $0.5 \mathrm{mg} / \mathrm{ml}-\mathrm{PBS}$ ) at $0^{\circ} \mathrm{C}$ for $30 \mathrm{~min}$. Labeled cells (ECA-positive cells) were separated by use of a magnet. Both the remaining cells (ECA-negative cells) and ECA-positive cells were used for the metastasis formation experiments by injecting the cells into the spleen of mice.

\section{Adhesion of platelets to cultured colon 26 cells}

A $0.5 \mathrm{ml}$ volume of PRP and $0.5 \mathrm{ml}$ test materials in PBS were added to a monolayer of cultured colon 26 cells in $35-\mathrm{mm}$ plastic dishes. After incubation at $37^{\circ} \mathrm{C}$ for 30 min, the dishes were washed with PBS and the colon 26 cells with more than one platelet attached to each cell were counted.

\section{Isolation of ECA-positive materials}

Liver metastatic foci of colon 26 cells were collected and homogenized in 20 volumes of $1 / 10$ diluted PBS containing $1 \mathrm{mM} \mathrm{CaCl}$. The homogenate was repeatedly
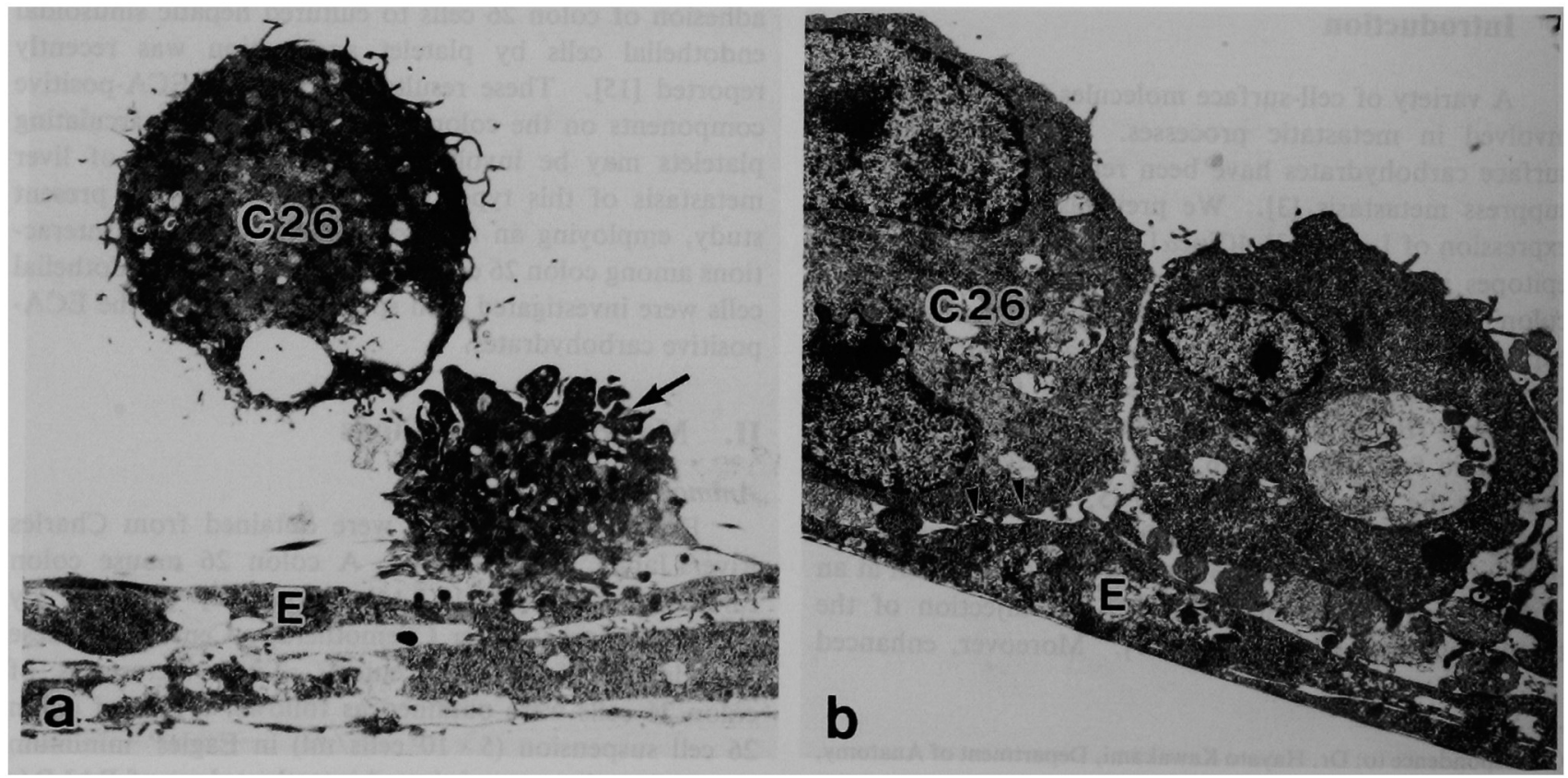

Fig. 1. Transmission electron micrographs of colon 26 cells incubated with HSE cells and PRP. (a) After 10 min of incubation. Colon 26 cells (C26) become indirectly attached to the monolayer of cultured HSE endothelial cells (E) sandwiched by aggregated platelets (arrow). $\times 4,800$ (b) By 30 min of incubation, the tumor cells (C26) have become directly attached to endothelial cells (E) (arrowheads). Some platelets still remain between tumor and endothelial cells. $\times 7,500$. 
washed with $1 / 10 \mathrm{PBS}$ at $1,500 \times \mathrm{g}$ for $10 \mathrm{~min}$ and the pellet (crude membrane and nuclei fraction) was solubilized with $1 \%$ NP40-PBS containing $30 \mu \mathrm{g} / \mathrm{ml}$ leupeptin at $0^{\circ} \mathrm{C}$ for $2 \mathrm{hr}$. The extract was collected by centrifugation at $20,000 \times \mathrm{g}$ for $1 \mathrm{hr}$ and then applied onto a column of ECA-agarose (Vector Lab.). The gel was thoroughly washed with PBS and the bound materials were then eluted with $0.4 \mathrm{M}$ lactose-PBS. The eluate was dialyzed against PBS and concentrated. SDS-gel electrophoresis was performed by the method of Laemmli [8], followed by transference of the protein to a PVDF membrane and staining with biotinylated ECA $(10 \mu \mathrm{g} / \mathrm{ml})$ by the $\mathrm{ABC}$ method.

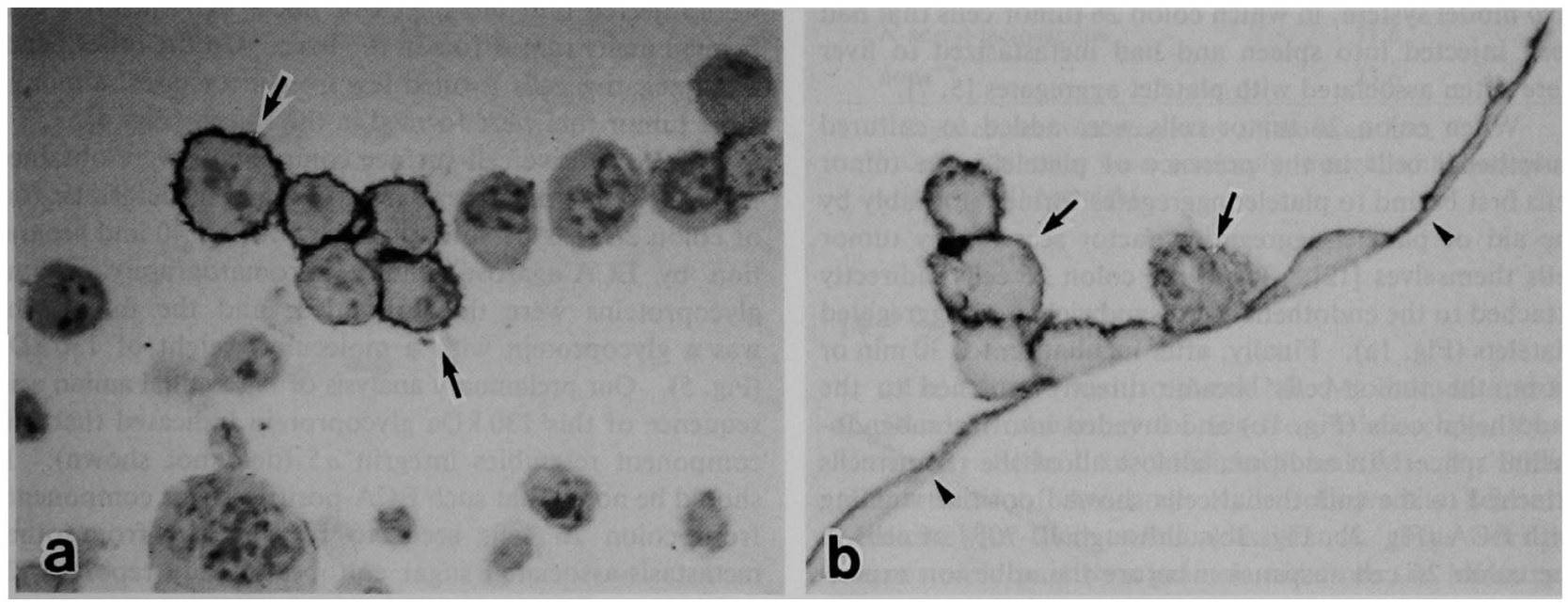

Fig. 2. Light micrographs of colon 26 cells incubated with HSE cells and PRP. Stained with ECA. (a) Before incubation. Mixture of colon 26 cells and PRP was washed, fixed and stained with ECA. Part of the tumor cell population (30-70\%) is positive for ECA (arrows). However, the remainder is negative. Stained slightly with toluidine blue. $\times 680$ (b) After 30 min of incubation. Almost all of the colon 26 cells (arrows) attached to HSE cells (arrowheads) reveal positive staining for ECA. $\times 740$.

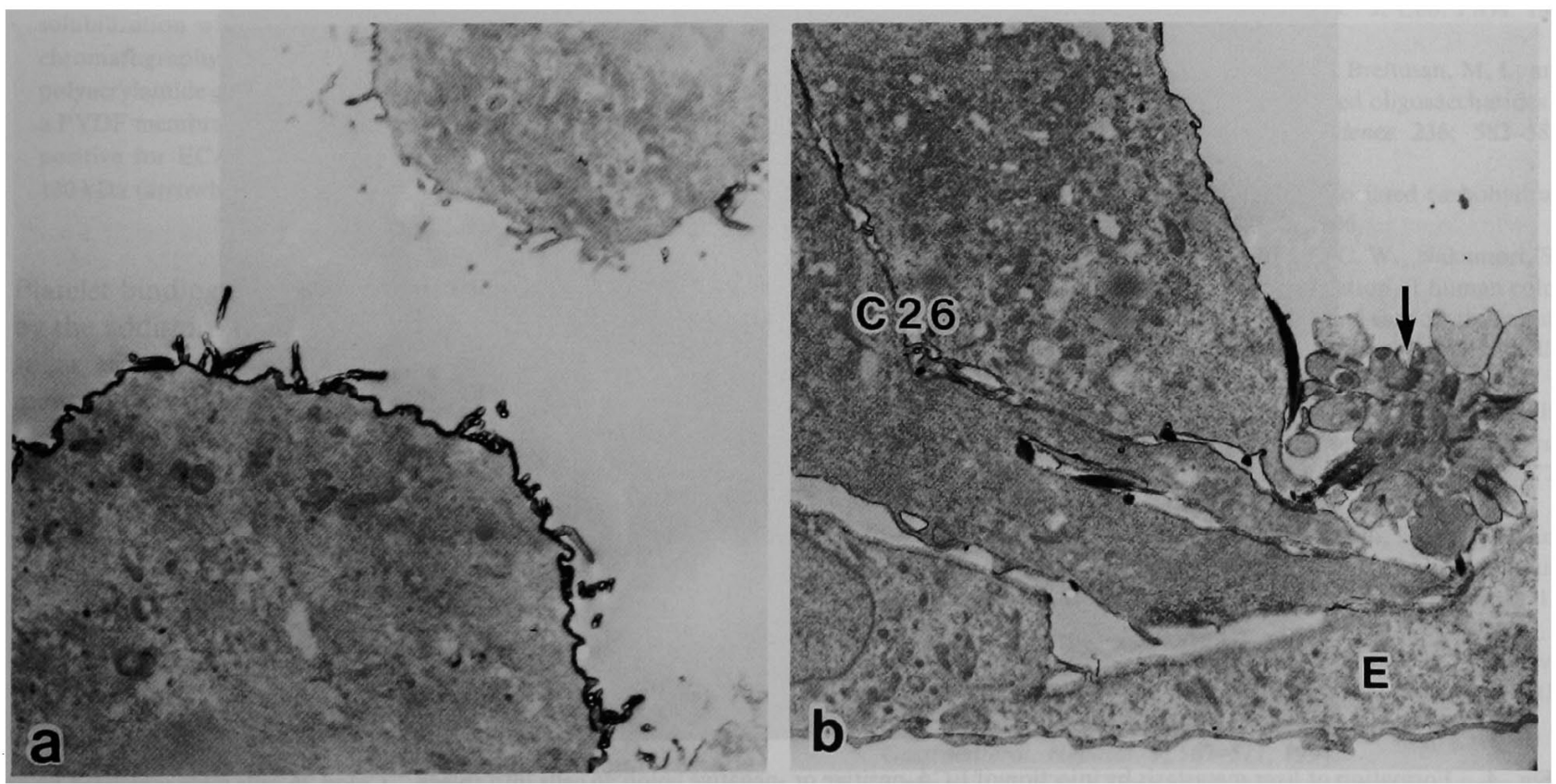

Fig. 3. Electron micrographs of colon 26 cells incubated with HSE cells and PRP. Stained with ECA. Ultrathin sections were post-stained with lead citrate. (a) Before incubation. The plasma membrane of some of the colon 26 cells is strongly positive for ECA, but that of others is only slightly positive. $\times 6,200$ (b) After 30 min of incubation. ECA-positive colon 26 cells (C26) are attached to HSE cells (E) associated with aggregated platelets (arrow). $\times 5,100$. 


\section{Results and Discussion}

Blood platelets are believed to contribute as one of the essential mediators to the binding between tumor and endothelial cells and to the establishment of metastasis [10]. In an in vitro system, as shown earlier [15] and in our present study, colon 26 tumor cells could hardly bind to cultured endothelial cells in the absence of platelets. The importance of platelets was already pointed out in our in vivo model system, in which colon 26 tumor cells that had been injected into spleen and had metastasized to liver were often associated with platelet aggregates [5, 7].

When colon 26 tumor cells were added to cultured endothelial cells in the presence of platelets, the tumor cells first bound to platelet aggregates formed probably by the aid of platelet-aggregating factor secreted by tumor cells themselves [12]. Then, the colon 26 cells indirectly attached to the endothelial cells sandwiched by aggregated platelets (Fig. 1a). Finally, after incubation for $30 \mathrm{~min}$ or more, the tumor cells became directly attached to the endothelial cells (Fig. 1b) and invaded into the subendothelial space. In addition, almost all of the tumor cells attached to the endothelial cells showed positive staining with ECA (Fig. 2b, Fig. 3b), although 30-70\% of cells in the colon 26 cell suspension before the adhesion experiment were negative for ECA staining (Fig. 2a, Fig. 3a). These results show that ECA-positive colon 26 cells selectively bound to endothelial cells by the aid of aggregated platelets. The ratio of ECA-positive colon 26 cells increased by the repeated formation of liver metastases, i.e., by re-injection of liver metastasized cells into the spleen of another mouse (data not shown). A colon 26 cell line with high metastatic potency toward the liver has been obtained in our laboratory by more than 20 repeated re-injection cycles.

ECA-positive colon 26 cells were separated by use of a magnetic cell sorting system comprising ECA and iron particles. When ECA-positive cells or ECA-negative cells were injected into the spleen of mice, ECA-positive cells formed many tumor foci in the liver. On the other hand, ECA-negative cells formed few liver metastases, although large tumor foci were formed in the spleen (Fig. 4).

ECA-positive cell-surface components were obtained from the crude membrane fraction of liver metastatic foci of colon 26 cells by solubilization with NP40 and separation by ECA-agarose affinity chromatography. Some glycoproteins were thus obtained, and the major one was a glycoprotein with a molecular weight of $130 \mathrm{kDa}$ (Fig. 5). Our preliminary analysis of $\mathrm{N}$-terminal amino acid sequence of this $130 \mathrm{kDa}$ glycoprotein indicated that this component resembles integrin $\alpha 5$ (data not shown). It should be noted that such ECA-positive sugar components from colon 26 cells seem to be different from other metastasis-associated sugar epitopes already reported [2, $4,9,11]$.

When this ECA-positive fraction of glycoproteins was added to the colon 26 cell culture, the binding of platelets to the colon 26 cells was significantly inhibited (Table 1).

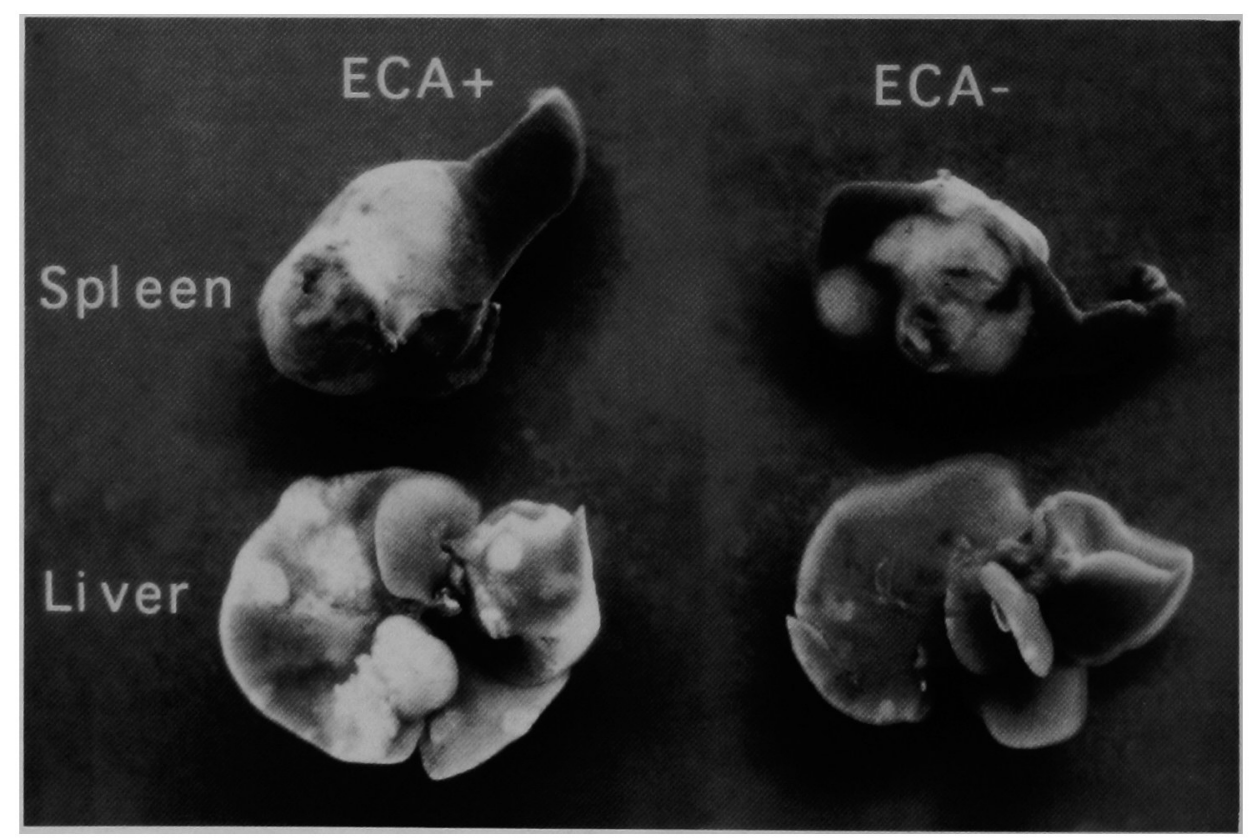

Fig. 4. Formation of liver metastasis by injection of ECA-positive or -negative colon 26 cells into spleen. Colon 26 cells were separated by use of magnetic cell sorting system comprising ECA and iron particles. A $0.1 \mathrm{ml}$ volume of ECA-positive (ECA+) or ECA-negative (ECA-) cell suspension $\left(5 \times 10^{5}\right.$ cells $\left./ \mathrm{ml}\right)$ was injected into the spleen of mice. After 2 weeks, both the liver and spleen were dissected out. ECA-positive cells formed many tumor foci in the liver. On the other hand, ECA-negative cells formed only a few liver metastases, although large tumor foci were formed in the spleen in each case. 


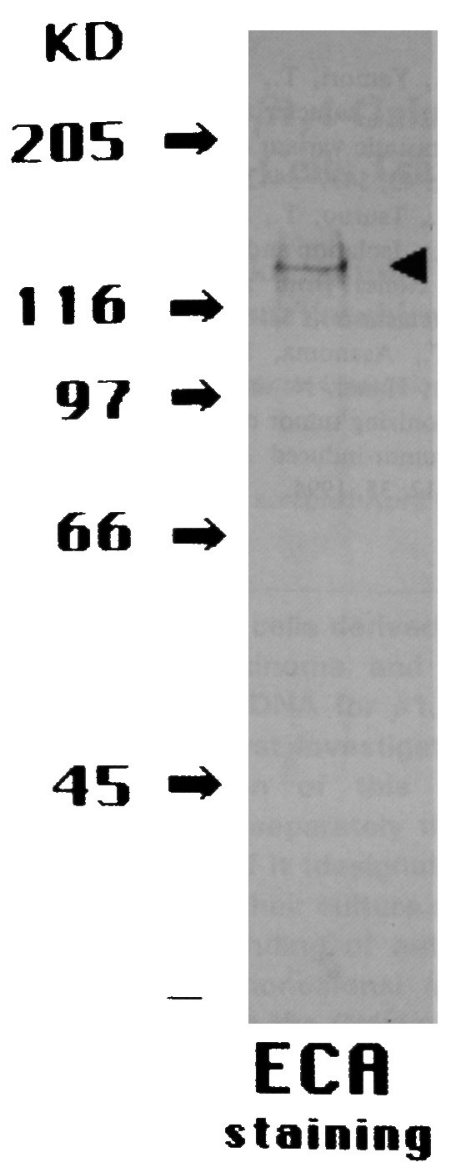

Fig. 5. ECA-blot analysis of colon 26 cell membrane extract. ECA-positive cell-surface components were obtained from the crude membrane fraction of liver metastatic foci of colon 26 cells by solubilization with NP40 and separation by ECA-agarose affinity chromatography. A $10 \mu \mathrm{g}$ amount of protein was applied to $9 \%$ polyacrylamide gel. After SDS-PAGE, samples were transferred to a PVDF membrane and stained with ECA. The major component positive for ECA was a glycoprotein with a molecular weight of $130 \mathrm{kDa}$ (arrowhead).

Platelet binding to colon 26 cells was also inhibited partly by the addition of $N$-acetyl-lactosamine, a specific hapten sugar structure bound by ECA. Interestingly, pretreatment of colon 26 cells with tunicamycin $(1.0 \mu \mathrm{g} / \mathrm{ml}$, overnight) strongly inhibited the binding of platelets to the tumor cells (Table 1). These results indicate that $N$-linked sugar chains, especially ECA-positive components on the tumor cell surface, are closely related to the interaction between tumor cells and blood platelets. Such tumor cells positive for ECA-staining, when decorated with platelets either in vivo or in vitro, may acquire the properties to interact easily with endothelial cells and to cause the successive events relating to the establishment of cancer metastasis. The nature of ECA-positive sugar residues and of their counterpart on the surface of platelets is now under investigation in our laboratory.
Table 1. Adhesion of platelets to cultured colon 26 cells. Mouse PRP was added to the cultured colon 26 cells in the presence or absence of test materials $(0.3 \mathrm{mg} \mathrm{sugar} / \mathrm{ml})$. After $30 \mathrm{~min}$ of incubation, the cells were washed with PBS and the numbers of colon 26 cells bearing more than one platelet were counted among more than 1,000 cells in each dish.

\begin{tabular}{lc}
\hline Test material & Colon 26 cells with platelets (\%) \\
\hline none & 67.0 \\
ECA-agarose eluate & 41.4 \\
$N$-acetyl-lactosamine & 51.6 \\
none $^{* *}$ & 23.6 \\
\hline
\end{tabular}

* Sugar content was assayed by anthrone method.

** Colon 26 cells were previously treated with tunicamycin $(1.0 \mu \mathrm{g} / \mathrm{ml})$ overnight.

\section{Acknowledgments}

The authors wish to thank Mr. M. Fukuda and Ms. C. Okada (Laboratory for Electron Microscopy, Kyorin University School of Medicine) and Ms. T. Shibata (Department of Anatomy, Kyorin University School of Medicine) for their technical assistance. This work was supported in part by a grant-in-aid from the Ministry of Education, Science and Culture of Japan.

\section{References}

1. Belloni, P. N. and Nicolson, G. L.: Differential expression of cell surface glycoproteins on various organ-derived microvascular endothelia and endothelial cell cultures. J. Cell. Phys. 136; 398-410, 1988.

2. Dennis, J. W., Laferté, S., Waghorne, C., Breitman, M. L. and Kerbel, R.S.: $\beta 1-6$ branching of asn-linked oligosaccharides is directry associated with metastasis. Science 236; 582-585, 1987.

3. Fukuda, M.: Possible roles of tumor-associated carbohydrate antigens. Cancer Res. 56; 2237-2244, 1996.

4. Izumi, Y., Taniuchi, Y., Tsuji, T., Smith, C. W., Nakamori, S., Fidler, I. J. and Irimura, T.: Characterization of human colon carcinoma variant cells selected for sialyl Le $\mathrm{L}^{\mathrm{x}}$ carbohydrate antigen: liver colonization and adhesion to vascular endothelial cells. Exp. Cell Res. 216; 215-221, 1995.

5. Kawakami, H., Ito, M., Miura, Y. and Hirano, H.: Lectinhistochemical studies of liver metastasis of mouse colon carcinoma (colon 26) cells. Acta Histochem. Cytochem. 25; 577$582,1992$.

6. Kawakami, H., Ito, M., Miura, Y. and Hirano, H.: Expression of Lewis ${ }^{\mathrm{X}}$ sugar structure in the liver metastasis of mouse colon carcinoma (colon 26) cells. Clin. Expl. Metastasis 12; 129-133, 1994.

7. Kawakami, H., Ito, M., Miura, Y. and Hirano, H.: Involvement of $\mathrm{N}$-acetyl-lactosamine-containing sugar structures in the liver metastasis of mouse colon carcinoma (colon 26 ) cells. $J$. Gastroenterol. Hepatol. 9; 567-571, 1994.

8. Laemmli, U. K.: Cleavage of structural proteins during the assembly of the head of bacteriophage T4. Nature 227; 680$685,1970$.

9. Le Marer, N. and Stéhelin, D.: High alpha-2,6-sialylation of $N$ acetyllactosamine sequences in ras-transformed rat fibroblasts 
correlates with high invasive potential. Glycobiology 5; 219226, 1995.

10. Nicolson, G. L.: Metastatic tumor cell interactions with endothelium, basement membrane and tissue. Curr. Opin. Cell Biol. 1; 1009-1019, 1989.

11. Takemoto, M., Shirahama, T., Miyauchi, T., Matsusako, T., Kaneda, N., Muramatsu, H., Ozawa, M., Ohi, Y. and Muramatsu, T.: Metanestin, a glycoprotein with metastasisassociated expression in transitional cell carcinoma of the urinary bladder. Int. J. Cancer 74; 7-14, 1997.

12. Toyoshima, M., Nakajima, M., Yamori, T. and Tsuruo, T.: Purification and characterization of the platelet-aggregating sialoglycoprotein gp44 expressed by highly metastatic variant cells of mouse colon adenocarcinoma 26. Cancer Res. 55; 767-
$773,1995$.

13. Tsuruo, T., Yamori, T., Naganuma, K., Tsukagoshi, S. and Sakurai, Y.: Characterization of metastatic clones derived from a metastatic variant of mouse colon adenocarcinoma 26. Cancer Res. 43; 5437-5442, 1983.

14. Yamori, T., Tsuruo, T., Naganuma, K., Tsukagoshi, S. and Sakurai, Y.: Isolation and characterization of highly and rarely metastatic clones from murine colon adenocarcinoma 26. Invasion Metastasis 4; 84-97, 1984.

15. Yamori, T., Asanoma, K., Shimada, K., Kawakami, H., Hirano, H., Hanai, N. and Tsuruo, T.: Enhanced adhesion of liver-colonizing tumor cells to hepatic sinusoidal endothelial cells by tumor-induced platelet aggregation. Clin. Expl. Metastasis 12; 35, 1994. 